\title{
¿EXISTE UN MODELO EUROPEO DE JUSTICIA CONSTITUCIONAL?*
}

\author{
POR \\ TANIA GROPPI \\ Catedrática de Derecho Constitucional. \\ Universidad de Siena

\section{LOS ORÍGENES DE LA JUSTICIA CONSTITUCIONAL EN EUROPA}

La justicia constitucional —entendida como técnica de defensa jurisdiccional de la Constitución frente a actos y comportamientos de los poderes públicos, incluida la ley del Parlamento ${ }^{1}$ - se desarrolla en el continente europeo en el siglo XX, más de cien años después, por tanto, de la sen-

* Traducido por Francisco M. Ruiz-Risueño Montoya

${ }^{1}$ La justicia constitucional — por su carácter jurisdiccional, al realizarse en la forma del proceso por un órgano imparcial, externo al circuito de la dirección política- debe considerarse distinta a las formas de garantía política de la Constitución, de las que se encuentran numerosos ejemplos en la historia de las Constituciones, desde los foros de la Constitución espartana hasta los distintos tipos de Senado (del romano al de las monarquías de la restauración) y más tarde, el Presidente de la República en las formas de gobierno parlamentario, v. G. Zagrebelsky, La giustizia costituzi,oHaMlenlino, 
tencia Marbury v. Madison(1803), con la que por primera vez en los Estados Unidos un juez ejerció el control de constitucionalidad de las leyes, en la forma de judicial review of legislation.

El origen de la justicia constitucional en Europa suele atribuirse a la Constitución austríaca de $1920^{2}$ y a su inspirador, Hans Kelsen ${ }^{3}$. Cuando se habla en términos más generales, es preciso referirse a los años inmediatamente posteriores a la primera guerra mundial ${ }^{4}$ : es entonces cuando ven la luz otras experiencias de justicia constitucional, como la checoslovaca (que precede de hecho a la austríaca, dado que el Tribunal constitucional checoslovaco comenzó a funcionar el 29 de febrero de 1920, mientras que el austríaco sólo lo hizo el 1ํㅡ de octubre de ese mismo año) o la de la Alemania de Weimar (en la que, desde 1925, en ausencia de una explícita prohibición constitucional, los jueces se reconocieron el poder de controlar las leyes del Reich ${ }^{5}$.

Ya durante el siglo $\mathrm{XIX}$, sin embargo, en las organizaciones estatales de tipo federal, como Suiza, el Imperio austro-húngaro o el Imperio alemán, había comenzado a afirmarse un particular "tipo" de justicia constitucional, la staatsgerichtsbarkeón el fin de ordenar la convivencia entre los distintos niveles de poder político en el Estado6: algunos tribunales federales tenían la función de defender las normas constitucionales de reparto de competencias entre Federación y Estados miembros, mediante la resolución de conflictos de atribución.

2 V. por ejemplo D. Rousseau, La justice constitutionnelle en Europe, Montchrestien, Paris, 1992, 13, y J. J. Fernández Rodríguez, La justicia constitucional europea ante el sigloTerros, Madrid, 2001, 27 ss.

${ }^{3}$ Sobre el papel de Kelsen en la redacción de la Constitución austríaca de 1920, v. M. OlivetTI, "La giustizia costituzionale in Austria (e in Cecoslovacchia)», en M. Olivetti, T. Groppi (coords.), La giustizia costituzionale in, Milano, 2003, 25 ss.

4 Habla de una real y verdadera "formación" del sistema europeo de control de constitucionalidad como de un proceso que tras las dos guerras implica, además de a Austria, a la Alemania de Weimar, a Checoslovaquia y a la España de la Segunda República, P. Cruz Villalón, La formaci n del sistema europeo de control de- consti tucionalidad (1918-19, EEC, Madrid, 1987.

${ }^{5}$ Sobre la Aufwertungsurte(isentencia sobre la revaluación) del Tribunal del Reich de 5 de noviembre de 1925, que constituye la Marbury v. Madisode la República de Weimar al establecer las bases teóricas de la judicial reviedrichterliches Pr fungsrech,tv. P. Cruz Villalón, La formaci n del sistema eur,citep88 ss.

${ }^{6}$ Para la distinción entre Verfassungsgerichtsbarkestaatsgerichtsbark®iA. PIzzorusso, "Commento all'art. 134", en Commentario della Costituz,iem G. Branca, "Garanzie costituzionali (artt. 134-139)", Zanichelli, II foro italiano, Bologna-Roma, 1981, 
Lo que, sin embargo, no se realizó en Europa hasta el siglo $X X$, con pocas y esporádicas excepciones ${ }^{7}$, a pesar de varias tentativas y propuestas en esa dirección (desde el jury constitutionndierSieyès de 1795 hasta el Verfassungsgerichtschof $f$ r stedealiedlinek de 1885) es el tipo de justicia constitucional que tiene como finalidad la protección de los derechos, individuales y sociales, reconocidos en la Constitución, especialmente contra la ley: la Verfassungsgerichtsbarkeit

Las razones son múltiples y complejas: pueden, con todo, reconducirse a las características de las monarquías constitucionales del siglo XIX y a la función que en ellas se atribuía a la Constitución.

En el Estado liberal de derecho, la Constitución se entiende como norma jurídica superior que expresa el resultado del compromiso entre el Monarca absoluto y la burguesía, limitando la plenitud de los poderes del Rey a favor de los ciudadanos burgueses representados en la asamblea electiva, elegida mediante sufragio censitario. En un contexto dualista, en el que quedaba sin respuesta la cuestión crucial de a quién correspondía la soberanía (al Rey o a la Nación o a sus representantes), era imposible confiar la garantía del compromiso, o mejor, de la Constitución, a una instancia imparcial. Cada una de las partes pretendía ser garante del compromiso: el Rey como residuo de su antigua soberanía, autolimitada por la concesión de la Constitución, la Cámara de representantes en cuanto la Constitución vincularía exclusivamente al Rey y a (su) administración, pero no a la ley votada por los representantes de la burguesía.

La evolución en sentido monista de las monarquías del siglo XIX no cambia, por lo que a nosotros interesa, la situación: el predominio burgués, la afirmación del régimen parlamentario y de la omnipotencia del Parlamento y de la ley condujeron a considerar la Constitución como texto flexible, o subordinado a las exigencias de las fuerzas políticas, que recibían expresión en la ley ordinaria. "No podía imaginarse entonces que la Constitución tenía como función obstaculizar el desarrollo de la vida política,

7 En algunos países, ya en el siglo XIX, los Tribunales supremos pronunciaron esporádicamente algunas sentencias que afirmaban su competencia para desarrollar un control incidental de constitucionalidad de las leyes, según el modelo estadounidense: es el caso de Grecia (1847), Noruega (1866), Portugal. M. Fromont, La justice constitu tionnelle dans le morDiadloz, Paris, 1996, 15.

${ }^{8}$ Acerca de las experiencias de justicia constitucional europeas en el siglo XIX, tanto las que tuvieron real aplicación (en los Estados federales) como las que se quedaron en mero proyecto, v. J. LUTHER, Idee e storie di giustizia costituzionale nel,l?ottocento 
tal y como la determinaban las fuerzas hegemónicas. Éstas, haciendo uso de la ley, podían convertir en "constitucional» lo que, aunque contradijera la Constitución, entraba en sus planes» ${ }^{9}$.

En otros términos, en la Europa del siglo XIX faltaba un elemento esencial para el nacimiento de la justicia constitucional, elemento que por el contrario estaba ya presente desde hacía mucho tiempo en los Estados Unidos: el pluralismo social y político. Sólo la existencia de una Constitución que se plantea como compromiso entre diversas fuerzas políticas y sociales para configurar un cuadro de principios compartidos, respecto al que cada una de las fuerzas no representa sino un fragmento, consiente (es más, exige) la creación de una justicia constitucional: sólo allí donde no está ya en juego la soberanía, y nos movemos en el ámbito de la "ordinaria" vida constitucional, puede existir una autonomía de la esfera constitucional y se puede delegar a un órgano imparcial la función de hacer vivir y respetar la Constitución ${ }^{10}$.

Hasta las grandes revueltas de la primera guerra mundial, la ampliación del sufragio, el nacimiento de los partidos políticos, el pluralismo estatal había consentido tan sólo la creación de la jurisdicción constitucional de los conflictos, la staatsgerichtsbarkeSólo tras la Primera Guerra Mundial y, después, de manera más decisiva, a partir de la segunda posguerra, se presentan en Europa las condiciones concretas para el nacimiento del control de constitucionalidad de las leyes, la Verfassungsgerichtsbarkeit.

2.- La expansión de la justicia constitucional en Europa en el siglo XX.

Si se observa hoy el continente europeo, puede afirmarse que el desarrollo de la justicia constitucional ha sido continuado y generalizado: con pocas, limitadas excepciones ${ }^{11}$, formas de defensa jurisdiccional de la Constitución, que comprenden el control de constitucionalidad de las

9 G. ZAGREBELSKY, La giustizia costituzioitą20-21.

10 De nuevo, G. ZAGReBelskY, La giustizia costituzioiłą 25 ss.

11 Sobre estas excepciones - que por el momento son el Reino Unido y los Países Bajos- v. F. RosA, "l paesi senza controllo di costituzionalità», en M. Olivetti, T. Groppi (coords.), La giustizia costituzionale in Giufføè,aMilano, 2003.

12 La justicia constitucional está presente incluso en los «microestados» (Andorra, San Marino, Malta, Principado de Mónaco, Liechtenstein) de los que no se ocupa este libro: v. al respecto, G. GuIDI (coord.), Piccolo stato, Costituzione e connessioni inter naziona 7 Giappichelli, Torino, 2003. 
leyes, están presentes en todos los ordenamientos ${ }^{12}$.

En Europa, la expansión de la justicia constitucional se ha producido en cuatro "oleadas» ${ }^{13}$.

Una primera oleada se produjo en el período de entreguerras, y comprende las experiencias constitucionales de Austria (1920), de Checoslovaquia (1920), de Liechtenstein (1921), de Rumania (1923) ${ }^{14}$, de la Alemania de Weimar (1925), de la Segunda República española (1931) y de Irlanda (1937). Dejando de lado el caso irlandés, se trata de experiencias que tuvieron una breve duración, y que sucumbieron como consecuencia de la caída de los regímenes democráticos cuya defensa les había sido encomendada bajo regímenes autoritarios; una prueba más de que en contextos caracterizados por un fuerte conflicto social es bastante difícil que la garantía de la Constitución pueda ser realizada por la vía "fría» de la jurisdicción ${ }^{15}$.

Una segunda oleada se produce en el período posterior a la segunda guerra mundial. Cuando, además del restablecimiento del Tribunal austriaco (1945), se prevén Tribunales constitucionales en Italia (1948) y en Alemania (1949); también la Constitución de la V República francesa (1958) y la turca de 1961 pueden ser incluidas en esta fase.

Una tercera oleada tiene lugar en los años setenta, con las Constituciones griega (1975), portuguesa (1976), española (1978), y la revisión de las Constituciones sueca (1979) y belga (1980).

La cuarta oleada afecta principalmente a los países de la Europa centro-oriental, a partir de la reforma de la Constitución húngara de 1989 para llegar hasta la nueva Constitución albanesa de 1998, pero comprende también a Luxemburgo (que revisa su Constitución en 1996) ${ }^{16}$ y a Finlandia (con su nueva Constitución de 1999).

Más allá del elenco de países y de fechas, lo que expresa esta enumeración es que la expansión de la justicia constitucional se ha producido

13 L. Favoreu, Les Cours constitutionne ${ }^{2}$ d., PUF, París, 1996, 4, en el que habla de "vagues».

${ }^{14}$ La Constitución de 1923 confiaba a la Corte de Casación la función de controlar la constitucionalidad de las leyes.

${ }^{15} \mathrm{~V}$. al respecto, en relación con la Constitución de Weimar y con los «compromisos dilatorios" en ella contenidos, en el sentido de que "la garantía de la estabilidad de aquella situación constitucional sólo podía ser de tipo político", G. ZAGREBELSKY, La gius tizia costituzipcitl, 23-24.

16 V. C. VITUCCI, "La prima decisione della Corte costituzionale del Granducato di 
en Europa, a partir de 1920, según una doble línea de tendencia, que parece posible encontrar también fuera del continente europeo.

En primer lugar, el desarrollo de la justicia constitucional se produce al mismo tiempo que la democratización: el nexo entre justicia constitucional y democratización es fácilmente perceptible desde las primeras experiencias a las que se ha hecho referencia y de hecho caracteriza la evolución de la justicia constitucional en cada una de las cuatro etapas indicadas, aunque resulte particularmente evidente en el caso de los países de la Europa mediterránea en los años setenta y en el de los países de la Europa centro-oriental en los años noventa.

Ya en el originario planteamiento kelseniano el nexo entre justicia constitucional y democracia está bien presente: la justicia constitucional se configura como un instrumento puesto en defensa de las minorías contra las manifestaciones de voluntad, contrarias a la Constitución, de la mayoría parlamentaria, funcionando como dique al nacimiento de una «dictadura de la mayoría» ${ }^{17}$.

En el continente europeo, como en otros lugares, es hoy inconcebible la adopción de una nueva Constitución democrática que no prevea formas de garantía jurisdiccional de su supremacía. La justicia constitucional se considera hoy elemento cardinal del Estado democrático. Es su ausencia la que puede hacer dudar del carácter democrático de un ordenamiento ${ }^{18}$. La experiencia de estas últimas décadas es clara en este sentido. Dondequiera que se ha asistido a un proceso de democratización, éste ha ido acompañado de la creación de órganos de justicia constitucional: así ha sido en África, en América Latina, en los países del centro y este europeos.

Por otra parte, la sola referencia a la democratización no es capaz por sí misma de explicar por entero la expansión de la justicia constitucional en Europa. Se ha asistido también al nacimiento de sistemas de justicia constitucional en ordenamientos ya democráticos, que en un cierto momento han

17 H. Kelsen, "La garantie jurisdictionnelle de la Constitution», en $R D P, 1928,197$ ss.

18 Son múltiples los documentos en este sentido adoptados por las organizaciones internacionales: véase, por ejemplo, por no salir del ámbito europeo, una de las primeras tomas de posición de la Comisión de Venecia, creada en el seno del Consejo de Europa para apoyar los procesos de democratización en los países del centro y este europeo, en la que se afirma: "Verification of the constitutionality of laws by the courts is a fundamental function in a State based on the rule of law" (Comisión de Venecia y CSCE, Seminario de Expertos en Instituciones Democráticas, Oslo, 4-15 de noviembre de 1991). 
aceptado someter la ley a alguna forma de control jurisdiccional. En estos casos, la justicia constitucional se ha introducido a través de una reforma constitucional, bien con ocasión de una revisión total (como en el caso de Francia o de Finlandia) o bien dirigida y limitada a este aspecto concreto (como ha sucedido en Suiza, Bélgica o Luxemburgo). Existen también en Europa casos de justicia constitucional que se han desarrollado, en la forma de control difuso, jurisprudencialmente, al margen de cualquier previsión constitucional específica: es el caso de algunos países escandinavos, como Dinamarca, Noruega o Suecia; sólo este último país ha dado posteriormente cobertura a esta práctica jurisprudencial en una ley constitucional ${ }^{19}$.

Más allá de las específicas razones y exigencias (piénsese por ejemplo en la relación entre transformación en sentido federal del Estado y justicia constitucional en Bélgica ${ }^{20}$, que han motivado el recurso a alguna forma de justicia constitucional en cada país, parece posible reconducir esta línea de evolución dentro del tema más general de la circulación de modelos; hoy se asume generalmente que es necesario establecer formas de defensa jurisdiccional de la Constitución, de forma que ningún tipo de acto (ni siquiera la ley parlamentaria) y ningún comportamiento político carezca de un juez que lo controle. Existe, en otros términos, un modelo de democracia constitucional que comprende entre sus elementos necesarios la justicia constitucional, y que representa un modelo hacia el que tender no sólo para las "nuevas democracias», sino también para las democracias consolidadas, dentro y fuera de Europa, de tal forma que se ha llegado a sostener que si el siglo XIX fue el siglo de los parlamentos, el siglo XX ha sido el de la justicia constitucional ${ }^{21}$.

Una prueba más de la existencia de esta segunda línea de tendencia, que va mucho más allá de la democratización, es que ordenamientos que tradicionalmente se han mostrado reacios a admitir cualquier tipo de control jurisdiccional de la ley, como los de tradición británica, han ido progresivamente plegándose a la necesidad de establecer alguna forma de justicia constitucional, como demuestran las experiencias de Sudáfrica, Canadá, Nueva

19 Sobre tales experiencias, v. V. TAMBURRINI, «I paesi con controllo diffuso di costituzionalità delle leggi», en M. Olivetti, T. Groppi (coords.), "La giustizia costituzionale in Europa", Giuffrè, Milano, 2003.

20 Sobre el sistema belga de justicia constitucional, v. el ensayo de F. RESCIGNo, "La justicia constitucional en Bélgica», y M.Verdussen, Les douze jugeBruxelles, 2004.

${ }^{21}$ Así, D. Rousseau, La justice constitutionnelle en cítu, $\$$ paritando a Mauro CAPPELLETti.

22 Sobre la tendencia, que parece irresistible, a la expansión de la justicia constitucional en el mundo, v. G. DE VERGOTTINI, Le transizioni costituzBohogńa, II Mulino, 1998, 82 ss.; M. Fromont, La justice constitutionnelle dans løitmo38le, 
Zelanda e Israel $^{22}$.

En Europa resaltan, en este sentido, las experiencias de los Países Bajos y del Reino Unido ${ }^{23}$. En los Países Bajos, a pesar de que permanece la disposición constitucional que veta a los jueces el control de la constitucionalidad de las leyes del Parlamento, los Tribunales desaplican las leyes contrarias al derecho comunitario y al Convenio Europeo de Derechos Humanos. También en el Reino Unido los jueces controlan las leyes del Parlamento en relación con el derecho comunitario, inaplicando las que lo contradicen, mientras que la Human Rights Acde 1998 ha reconocido que en caso de contraste entre una ley británica y los derechos previstos por el Convenio Europeo el juez puede declarar esta incompatibilidad, solicitando del legislador su intervención para modificar la disposición censurada.

En otros términos, la «intangibilidad» de la ley del parlamento para los órganos ajenos a la función de dirección política también ha sido puesta en duda en estos países, debido a factores externos a los ordenamientos nacionales, y no es difícil imaginar cuál será la evolución futura.

El derecho europeo y el derecho internacional de los derechos humanos juegan por tanto un papel decisivo en el probable caso de que se verifique una quinta oleada de justicia constitucional en Europa, que logre incluso afectar también a los países que hasta hoy son extraños a ese instituto. Sin embargo, derecho supranacional y derecho internacional inciden en el desarrollo de la justicia constitucional en Europa también de otra manera, que parece andar en una dirección opuesta a la apenas mencionada. En efecto, si es verdad que en los ordenamientos nacionales va creciendo el papel del derecho comunitario y del derecho internacional, que prevalecen sobre las fuentes internas, debe recordarse que se trata de normas emanadas por ordenamientos que tienen sus propios jueces, al menos de vértice, encargados de la interpretación y aplicación de ese derecho. En otras palabras, también el Tribunal Europeo de Derechos Humanos, el Tribunal de Estrasburgo, y el Tribunal de Justicia de las Comunidades Europeas, el Tribunal de Luxemburgo, adquieren espacio y competencias, en menoscabo de las jurisdicciones nacionales, comprendidas las constitucionales ${ }^{24}$.

Por tanto, expansión ininterrumpida de la justicia constitucional,

23 Sobre los cuales, v. F. Rosa, cit.

24 Sobre este desarrollo véase P. FalzeA, A. Spadaro, L. Ventura, La Corte costi tuzionale e le Corti d?ET̃ripo, Giappichelli, Giappichelli, 2003. 
como elemento que caracteriza el escenario de la democracia europea del siglo $\mathrm{XX}$, pero en el horizonte, en paralelo con la cesión de soberanía del Estado-nación, la tendencia al surgimiento de sistemas supranacionales de justicia constitucional, que se superponen (literalmente) o reemplazan a los que hasta hoy hemos conocido.

\section{3.- ¿EXISTE UN MODELO EUROPEO DE JUSTICIA CONSTITUCIONAL?}

La construcción de un modelo europeo de justicia constitucional nace históricamente de la contraposición con la judicial review of legisla tiorde los Estados Unidos y de la constatación de que éste tuvo una recepción algo limitada en el continente europeo. Rechazada la judicial review la creación de la justicia constitucional en Europa siguió un camino distinto y original, dando lugar, en las Constituciones checoslovaca y austríaca de 1920 a un modelo diferenciado, la Verfassungsgerichtbarkeit

Los principales elementos que diferencian a los dos modelos clásicos fueron ya evidenciados hace tiempo, así como las razones que han impedido la recepción del modelo norteamericano ${ }^{25}$.

Además de sus distintas características ideales (por el que el sistema estadounidense recibe la impronta del iusnaturalismo, de la idea de la Constitución como ley superior en cuanto tabla de valores, mientras que el austríaco es un producto del positivismo jurídico y aparece como lógica coronación del principio de legalidad) ${ }^{26}$, las diferencias entre ambos modelos se reconducen a tres aspectos relativos al control de constitucionalidad de las leyes y que se refieren: a) al órgano que ejerce el control de constitucionalidad; b) el modo en que tal control se activa; c) los efectos de las sentencias de inconstitucionalidad.

El modelo estadounidense se caracteriza por ser difuso, incidental y declarativo. Difuso porque todo juez está legitimado para ejercer el control de constitucionalidad. Incidental porque el control se desarrolla como "incidente» en el ámbito del un juicio que tiene un objeto distinto, respecto al que se presenta como una cuestión prejudicial: se trata de un control concreto, que se verifica en el momento en que la ley debe aplicarse a un caso concreto. Declarativo porque la sentencia mediante la que se

25 Por todos, v. M. CAPPELletTI, Il controllo giudiziario di costituzionalit delle leg, nel diritto compar Midano, Giuffrè, 1968.

26 Sobre las que puede verse por ejemplo A. Pizzonusso, "Commento all'art. 134», cit., 4 ss. 
inaplica una ley inconstitucional se limita a declarar la invalidez, ab origi ne, de la ley por ser incompatible con la Constitución, sin anularla, aplicando directamente la Constitución: los efectos de la sentencia son retroactivos (ex tunke inter part@e ahí deriva un sistema de justicia constitucional fuertemente dominado por la tutela de los derechos subjetivos, en relación con el que el control de la ley se produce per incidenen procedimientos judiciales que implican concretamente los derechos de las partes y en los que las razones del legislador no encuentran ningún espacio de representación ${ }^{27}$.

El modelo austríaco (en el planteamiento original de 1920) es concentrado, principal y constitutivo. Concentrado porque la función de juzgar la constitucionalidad de las leyes se niega a la generalidad de los jueces y de los operadores jurídicos y se reserva, por el contrario, a un órgano al efecto. Principal porque el control de constitucionalidad se solicita en vía de acción, mediante un recurso dirigido a obtener un control abstracto de la compatibilidad de la ley con la Constitución, independientemente de una concreta aplicación de ésta. Constitutivo porque las sentencias con las que se declara la inconstitucionalidad de la ley determinan su derogación, ex nuncy erga omnes, sin prejuzgar las posibles aplicaciones que la ley hubiera tenido en el pasado. Se trata de un sistema dirigido esencialmente a asegurar la constitucionalidad del derecho objetivo, mediante la eliminación de las leyes inconstitucionales, y que ha encontrado su culminación allí donde, como en la experiencia francesa, el control de constitucionalidad se desarrolla únicamente a prio,rántes de la entrada en vigor de la ley: aquí la tutela de los derechos aparece como una simple consecuencia de la conformidad de la ley a la Constitución.

Los motivos del rechazo, en el continente europeo, de la judicial revie ${ }^{28}$ son múltiples, y pueden ser fácilmente reconstruidos a través del examen de los trabajos preparativos que han conducido, en los distintos

27 Así G. Zagrebelsky, II diritto,nEinaudi, Torino, 1992, 78 ss.

28 Rechazo que es explícito en aquellas disposiciones constitucionales, como el art. 89 de la Constitución austríaca de 1920, que niegan a los jueces el poder de inaplicar las leyes. Justamente para impedir la inaplicación que, según la escuela de Viena, no necesitaba ninguna proclamación constitucional, siendo la lógica y necesaria consecuencia de la jerarquía normativa, se crean jueces especiales para el control de constitucionalidad: v. P. CRUz VILLALón, «Dos modos de regulación del control de constitucionalidad: Checoslovaquia (1920-1938) y España (1931-1936)», en REDC, 1982, 117.

29 Una síntesis de los intentos para introducir en distintos países europeos el modelo estadounidense, y de los motivos de su fracaso, puede encontrarse en L. FAVOREU, Les Cours constitutionnecite,5ss. 
países, a la introducción de la justicia constitucional, especialmente en la primera y en la segunda "oleada»" 29 .

Pueden reconducirse esencialmente a dos, uno de naturaleza estrictamente jurídica y otro de naturaleza más propiamente político-institucional.

En el plano jurídico, debe recordarse la inexistencia, en los sistemas europeos de civil len los que la libertad interpretativa de los jueces vale en los límites de la ley, de un principio comparable al de stare decisá \$a regla del precedente vinculante, que en los sistemas de common law, como el estadounidense, hace que cuando se declara la inconstitucionalidad de una ley por el Tribunal Supremo la eficacia de la sentencia sea prácticamente operante erga omnes, porque todos los jueces deben conformarse a ésta. En ausencia de stare decisébriesgo de que se establezca una jurisprudencia desacorde acerca de una cuestión tan crucial como la de la aplicación o inaplicación de una ley es elevado, con relevantes consecuencias sobre los principios de certeza del derecho y de igualdad de los ciudadanos ante la ley.

Sobre el plano político-institucional es determinante la distinta concepción existente en Europa del principio de separación de poderes y, sobre todo, del papel del poder judicial, madurada en la lucha contra el absolutismo real. Si en los Estados Unidos el juez asumía un papel de liberador frente a la opresión del Parlamento inglés, el juez europeo era visto, por el contrario, como un funcionario del Rey, y como auxiliar en la realización de tal opresión, mientras que el Parlamento aparecía como el verdadero defensor de los derechos de libertad, en cuanto expresión de la soberanía nacional. La desconfianza frente al poder judicial, heredada de la Revolución francesa (baste pensar en el $r$ f $r$ legis zeni firtud del cual correspondía al poder legislativo la función de interpretar en última instancia la ley oscura), es difícil de eliminar sobre todo en Francia, bien sintetizada en el título del libro de Lambert sobre el "gouvernement des juges ${ }^{30}$, y es fuerte también en los ordenamientos que introducen la justicia constitucional despúes de un proceso de democratización, en los que la magistratura ordinaria continúa estando compuesta por jueces formados y seleccionados en el precedente ordenamiento no democrático. Por lo demás, también en los países en los que tal desconfianza no era tan fuerte como para excluir de raíz el control difuso, como los países escan-

30 V. E. LAMBERT, Le gouvernement des juges et la lutte contre la l gislation sociales aux tats-Unis; le exp rience am ricaine du contr le judiciaire de la cons tutionalit des, lGirad, Paris, 1921. Sobre la importancia de esta obra en el acrecentamiento de la desconfianza hacia la judicial revilunt. Favoreu, Les cours con 
dinavos, la experiencia práctica ha demostrado la timidez del poder judicial y su renuencia a desarrollar un juicio de constitucionalidad, de modo que esta competencia ha sido utilizada, si se excluyen las primeras sentencias que en todo ordenamiento han reconocido su existencia, con gran cautela ${ }^{31}$.

En definitiva, en el continente europeo se rechaza -con las excepciones ya citadas- el elemento característico del modelo estadounidense, esto es, su carácter difuso. Este rechazo se produce en nombre del «privilegio del legisladorn: la ley, producto del Parlamento, el órgano representativo, no puede ser puesta en las manos de los jueces de carrera, sino que tiene su juez especial, distinto del de la magistratura ordinaria, caracterizado por una particular sensibilidad política que deriva de su especial composición, sobre la que inciden, con variedad de formas, los órganos políti$\cos ^{32}$. Por lo tanto, la ley vincula a todos los jueces hasta que no se declara inconstitucional por el órgano exclusivamente competente para contro-

31 Acerca de la incapacidad de los jueces comunes para ejercer la justicia constitucional, que tiene que ver con la "tradicional debilidad y timidez del juez continental» en cuanto juez de carrera, desprovisto de cualquier investidura democrática a diferencia del juez estadounidense, v. M. CAPPELLETTI, en L. FAVOreu (coord.), Cours constitutionnelles europ ennes et droits fondamentFoonomica-PUAM, Paris-Aix-en-Provence, 1982, 463.

${ }^{32}$ Característica del modelo europeo, por tanto, no es la de la concentración del control en un único órgano, interno o externo al poder judicial, sino la concentración del control en un juez especial, un juez ad hoc en esto se diferencia de experiencias en las que el control es concentrado, pero en las manos de un Tribunal Supremo, como sucede en algunos países de Latinoamérica. Sobre estas experiencias v. D. GARCía BeLAUNDE, F. Fernández Segado (coord.), La jurisdicci n constitucional en Iberolykinison, Madrid, 1997.

33 Así G. Zagrebelsky, La giustizia costituzi oitą168. En relación con el "privilegio del Legislador", v. BVerfG, I Senado, 20 de marzo de 1952, en BVerfGE 1952, 195 ss, en la que se afirma que "justamente el peligro para el poder legislativo, que deriva de la atribución a todos los jueces de la competencia para controlar la validez de la ley, fue una de las preocupaciones principales que motivó el que no se admitiera un poder de control generalizado de los jueces. Esto se ha evitado porque el control de constitucionalidad ha sido confiado a órganos especiales, "participados" por el mismo poder legislativo. Además, se ha aceptado que Constitución y ley serían del mismo rango, y por tanto que serían igual legislador constitucional y legislador ordinario, si no existiera un órgano especial competente para reformar la Constitución. Se ha llegado también a la conclusión de que el juez está vinculado a la ley promulgada formalmente de manera correcta, hasta que no sea declarada expresamente contraria a la Constitución. Finalmente, del principio fundamental de separación de poderes se ha deducido la obligación para los jueces de reconocer (la fuerza vinculante de) los actos del poder legislativo". 
lar sus vicios ${ }^{33}$

El "privilegio del legislador» es por tanto el elemento del modelo austríaco clásico que se recibe en casi todos los ordenamientos europeos en las "oleadas" sucesivas, hasta la más reciente. Puede considerarse por tanto a día de hoy característica esencial del modelo europeo de justicia constitucional ${ }^{34}$.

Sin embargo, desde la "segunda oleada" de expansión de la justicia constitucional en Europa, dos elementos determinan su alejamiento del ideal kelseniano.

En primer lugar, tanto la Constitución italiana de 1948 (para ser más precisos, la ley constitucional núm. 1/1948, casi contemporánea con ésta) y la alemana de 1949 prevén, junto al control abstracto de las normas, un control concreto, que se activa en vía de excepción, a través de una cuestión de constitucionalidad promovida, de oficio o a instancia de parte, por un juez común en el curso de un proceso, en el momento en que debe aplicar una norma a un caso concreto ${ }^{35}$.

Por lo tanto, también en los sistemas de justicia constitucional concentrada como los europeos, los jueces comunes están desvinculados de la obligación de aplicar siempre y en todo caso la ley cuando la consideren inconstitucional: cierto, no pueden inaplicarla, como sucede en los sistemas de control difuso, pero se establece una tercera vía, intermedia entre la obligación de aplicarla y la posibilidad de no aplicarla, que permite al juez suspender el proceso y remitir la cuestión de inconstitucionalidad, en vía incidental, al juez especial. La introducción del juicio concreto en sistemas concentrados determina relevantes efectos también sobre las sentencias de inconstitucionalidad, que adquieren carácter anulativo, manteniendo eficacia erga omnes, pero retroactiva. Elementos del sistema difuso, por tanto (el carácter concreto del proceso, los efectos retroactivos de las

${ }^{34}$ En el sentido de que "con la expresión 'modelo europeo' se hace simplemente referencia a la institución especializada y centralizada del control de constitucionalidad que existe en la mayoría de los países europeos, inspirada en la doctrina kelseniana y que parece adaptarse bien a los regímenes postautoritarios", P. PASQUINO, "Tipologia della giustizia costituzionale in Europa", en Riv. Trim. Dir. P, 220011., 299; de manera análoga, L. FAVOREU, Les Cours constitutionne,l đitas 5, para quien en el modelo europeo "el contencioso constitucional está... reservado en exclusiva a un tribunal creado ad hoccon esta finalidad".

35 Por lo demás, la posibilidad de acudir al Tribunal constitucional en vía incidental la admitió ya, aunque limitadamente para las jurisdicciones superiores, la reforma constitucional austríaca de 1929. 
sentencias), penetran en los sistemas concentrados, obligando a la doctrina a hablar de una superación de la distinción entre sistemas con control difuso/sistemas con control concentrado para clasificar los sistemas en sistemas concretos/abstractos de justicia constitucional ${ }^{36}$.

Más allá de las clasificaciones, siempre opinables, debe subrayarse que el modelo europeo de justicia constitucional, a pesar de la presencia en él de elementos propios del modelo estadounidense a causa de la introducción del control concreto, continúa negando a los jueces comunes la posibilidad de inaplicar las leyes contrarias a la Constitución: en otros términos, continúa existiendo un sistema "de privilegio del legislador». Lo que se introduce con la experiencia alemana e italiana, mediante el control concreto, es la posibilidad, para los jueces comunes, de "rebelarse" contra las leyes inconstitucionales, dirigiéndose al juez especial del legislador. Esta posibilidad hoy está presente, con la única excepción de Francia, en todos los sistemas europeos ${ }^{37}$ y puede por tanto ser considerada justamente una característica del modelo europeo de justicia constitucional ${ }^{38}$.

Además, la Constitución alemana de 1949, seguida por la española de 1978 y después por otros países, especialmente del este y centro europeo, ha previsto, inspirándose en la experiencia suiza, una competencia más, que se suma a las tradicionales de los órganos de justicia constitucional (control jurisdiccional de constitucionalidad de la leyes, resolución de los conflictos constitucionales): la defensa de los derechos fundamentales reconocidos en las Constituciones (Verfassungsberschwerderecurso de amparo). Se trata de un proceso constitucional de carácter concreto y subjetivo, que tiene naturaleza residual y subsidiaria, que sirve de garantía última de los derechos fundamentales, cuando han sido agotados todos los remedios que ofrece la justicia ordinaria y administrativa. Aunque exis-

${ }^{36}$ De este modo, A. PIzzorusso, «I sistema di giustizia costituzionale: dai modelli alla prassi», en Quad. Cost,. 1982, 521 ss; una clasificación similar la hace también M. Fromont, La justice constitutionnelle dans leitmdidss. El desarrollo de los sistemas europeos en la dirección del control difuso es subrayado, con referencia a Italia, en E.Malfattl, R.Rombol, E.Rossl, Il giudizio sulle leggi e la sua diffusione. Verso un controllo di costituzionalit di tidobiapipfftuesti? Torino, $2002 \mathrm{y}$, en general, en V.FeRRERES COMELLA, "The European Model of constitutional review of legislation: Toward decentralization?», in I. CON 2004, 461 ss.

37 Un elenco en J. J. Fernández Rodríguez, la justicia constitucional europea ante el siglo xeir., p. 71.

$38 \mathrm{Al}$ respecto se habla de un tertium genuscomo resultado de la hibridación de los primeros modelos: L. Pegoraro, Lineamenti di giustizia costituzionale comparata Giappichelli, Torino, 1998, 27. 
ten diferencias al respecto entre los dos países de referencia (en Alemania, objeto de recurso puede ser todo tipo de acto, legislativo, administrativo o judicial, mientras en España se excluye el amparo frente a leyes) ${ }^{39}$, en ambas experiencias este tipo de competencia absorbe la gran parte del trabajo de ambos Tribunales Constitucionales y, dado que la mayoría de los recursos son contra sentencias, el juez constitucional acaba por convertirse, de forma más o menos indolora, en órgano judicial supremo que uniforma la jurisprudencia de las más altas instancias.

A la luz de este desarrollo, algunos autores han introducido una ulterior clasificación de modelos de justicia constitucional, distinguiendo un modelo "centrado en la ley», o mejor, en la eliminación del ordenamiento jurídico de las normas inconstitucionales, y un modelo centrado en la defensa de los derechos. El modelo centrado en la ley encuentra su aspecto característico en el control abstracto mientras que el modelo centrado en la defensa de los derechos lo encuentra en el control concreto y en el recurso directo individual: la tendencia de los sistemas europeos es la de un desplazamiento del primero al segundo modelo, esto es, hacia una jurisdicción constitucional fundada en la defensa de los derechos, lo que encontraría explicación en el espacio adquirido por el recurso en defensa de los derechos fundamentales ${ }^{40}$.

Con todo, un examen de las experiencias europeas de justicia constitucional demuestra los límites de tal clasificación: el recurso directo para la defensa de los derechos fundamentales está presente en muchos países, además de los de origen, pero su difusión está muy lejos de convertirlo en un aspecto caracterizante del modelo europeo de justicia constitucional ${ }^{41}$. Y aún más si se considera que éste existe también de manera bastante más significativa y difundida en otras experiencias como las latinoamericanas ${ }^{42}$.

Este ejemplo demuestra cómo, ya a partir de la "segunda oleada", por no hablar de las sucesivas, el modelo se complica, de tal forma que

${ }^{39}$ Y se podría citar el caso de Austria, en la que el recurso directo no se admite contra las sentencias.

40 F. RUBio LLORENTE, "Tendences actuelles de la jurisdiction constitutionnelle en Europe", en Ann. Inter. Justice Con, XHL, 1996, Economica-PUAM, Paris-Aix-enProvence, 1997, 16 ss.

41 J. J. FernándeZ RodrígueZ, La justicia constitucional europea ante edit.siglo XXI, que se refiere, además de a Austria, a Albania, Croacia, República Checa, Eslovaquia, Eslovenia, Hungría, Macedonia, Polonia y Rusia.

$42 \mathrm{~V}$. al respecto muchos de los ensayos contenidos en el volumen de E. FerRerMAcGregor (coord.), Derecho procesal constituc,illiedl, Porrúa, México, 2002. 
ante la existencia de múltiples diferencias y peculiaridades se va dificultando progresivamente la individuación de elementos comunes a un hipotético "modelo europeo de justicia constitucional» más allá de los dos ya referidos: la existencia de un juez especial para el legislador (en virtud del privilegio que se confiere a este último) y la presencia conjunta de un control abstracto y de control concreto.

La línea de tendencia en la evolución de los sistemas europeos de justicia constitucional es la de la "suma progresiva», según una regla con base en la cual los sistemas más recientes son mucho más complejos que los precedentes, en cuanto que reciben todo el instrumental que ofrece el "mercado" del derecho comparado tanto en términos de vías de acceso al control de constitucionalidad de las leyes como en relación con la tipología y los efectos de las sentencias, como de "otras competencias" de los Tribunales Constitucionales ${ }^{43}$. La experiencia de los países de la Europa centro-oriental es, desde este punto de vista, emblemática; y no es casualidad que el sistema de justicia constitucional que ha ejercido la mayor influencia en esos países haya sido el alemán, seguramente el más rico y complejo entre los más maduros.

Si en parte la complejidad de los modelos puede explicarse por razones conectadas con la tradición jurídica de los distintos paíse ${ }^{44}$ o ligadas a la situación político-institucional del momento constituyente ${ }^{45}$, se trata de una tendencia sin embargo que afecta también a otros ámbitos del derecho constitucional, además de a la justicia constitucional. Ésta tiene que ver con el uso que del derecho comparado, en la forma de la «ingeniería constitucional", se hace con mucha frecuencia: la extrapolación de institutos y su transplante artificial a contextos profundamente diferentes, con resultados no siempre felices. A esto se suma la idea, recurrente pero errada, de que el nivel de tutela de los derechos aumenta cuanto más se multiplican las sedes y los instrumentos de tutela.

\section{4.- JUSTICIA CONSTITUCIONAL Y DEMOCRACIA}

43 Sobre las "otras» competencias de los Tribunales Constitucionales, v. L. Pegoraro, Lineamenti di giustizia costituzionale cocitaquatass.; S. BALdin, Le "altre" funzioni delle Corti cost,iEUJífriesté, 2000.

44 Es este el caso de Portugal.

45 Por ejemplo, la ya citada desconfianza hacia los jueces comunes en los países del centro y este europeo. 
El mayor éxito de la justicia constitucional en Europa, que se comprueba tanto por su progresiva y continua difusión como por las opiniones, frecuentemente muy positivas, que se dan sobre cada experiencia particular, no puede decirse que este proceso se haya realizado sin dificultades, ni que la clásica pregunta, presente desde el inicio de la experiencia estadounidense de justicia constitucional hace ya doscientos años, a saber, ¿cómo, y sobre la base de qué legitimidad, pueden nueve jueces deshacer lo que los representantes del pueblo, democráticamente elegidos, han querido?, haya quedado definitivamente archivada.

La pregunta continúa sin una respuesta definitiva en los países con la experiencia más antigua de justicia constitucional y pende como una guillotina sobre los Tribunales constitucionales de nueva creación. Y el debate es más acentuado en los Estados Unidos, patria de la justicia constitucional, que en los ordenamientos de tradición europea, caracterizados por la centralidad de la ley y por la supremacía del Parlamento ${ }^{46}$.

A pesar de la opción hoy casi universal por Constituciones rígidas, resulta evidente la dificultad para admitir que exista una esfera de la justicia (y de sus garantes) desvinculada de la esfera de la política (y de sus mayorías).

Múltiples son los síntomas de la permanente tensión entre justicia constitucional y democracia, que van desde las simples palabras (las declaraciones de algunos exponentes de las mayorías políticas coyunturales que se "rebelan" contra las decisiones de los tribunales constitucionales), a tentativas de influir subrepticiamente en la composición de la Corte para adquirir su control (por ejemplo, modificando el número de sus componentes, o revocándolos, o haciéndolos de cualquier forma decaer antes de término), a propuestas de reforma del sistema de justicia constitucional (el que vayan a buen término es secundario), a la inaplicación de las decisiones no gratas a las mayorías políticas (mediante una nueva aprobación de las leyes declaradas inconstitucionales o la inercia en ejecutar las sentencias). También el recurso a la

46 Sobre el tema, son de consulta obligada los clásicos A. BICKEL, The Least Dangerous BranchNew Haven, 1962; J. H. ElY, Democracy and Distrust: A Theory of Judicial Reviłtharvard University Press, Cambridge, Mass., 1980; más reciente, V. Ferreres Comella, Justicia constitucional y dem,CEeBG,i Madrid, 1997, además de los textos recogidos en W. SAdURSKI (coord.), Constitutional Justice, East and West. Democratic Legitimity and Constitutional Courts in Post-Communist Europe in a Comparative Perspectikku,wer Internacional, The Hague-London-New York, 2002. 
reforma constitucional "contra» las decisiones del juez constitucional es un indicador de esta tensión. Es cierto que el «derecho a la última palabra», en la dialéctica entre justicia constitucional y legislación constitucional, incumbe a esta última, pero se trata evidentemente del último recurso de la política ${ }^{47}$.

Muchos son también los intentos de encontrar formas de convivencia entre las dos esferas, la de la justicia (constitucional) y la de la política.

La doctrina, por su parte, se ha preocupado desde un principio de elaborar teorías para justificar la presencia de la justicia constitucional en las democracias. Desde la teoría kelseniana de la democracia como compromiso, en la que al tribunal constitucional correspondería desarrollar una función antimayoritaria, a aquella de la democracia deliberativa y procedimental de Habermas, en la que la legitimidad del tribunal constitucional derivaría de su diálogo continuo con el legislador y de la apertura de un espacio público de debate ${ }^{48}$.

Muchas son, por otro lado, las soluciones normativas que ofrece el derecho comparado.

La más evidente es justamente la opción por sistemas concentrados de justicia constitucional, caracterizados por la existencia de un juez «especial» encargado de controlar la constitucionalidad de las leyes.

La "especialidad" de los jueces constitucionales se descubre ya en su composición, en la que intervienen, de manera más o menos acentuada, los sujetos políticos. La opción por un sistema concentrado de justicia constitucional, cuyo ejercicio corresponde a un órgano ajeno al poder judicial, responde en parte a la búsqueda de un compromiso entre las exigencias del derecho constitucional y las exigencias de la política.

La amplitud de las competencias de estos «jueces especiales" en los diversos ordenamientos expresa la dificultad, más o menos severa, y la necesidad, más o menos imperiosa, de encontrar el compromiso: a sistemas en los que el juez constitucional es especial sobre todo por el objeto de control (la Ley del Parlamento, mientras el control de constitucionalidad de los otros actos incumbe a los jueces comunes), se con-

${ }^{47}$ Respecto al "derecho a la última palabra», v. L. FAVOREU, "La légitimité du juge constitutionnel», en Revue Internationelle de Droit Coin994, 557 ss.

48 V. H. Kelsen, "La garantie jurisdictionnelle de la Constitution", en RDP, 1928; J. Habermas, Fatti e norme. Contributi a una teoria discursiva del diritto e della dem raci,aMilano, Guerini e associati, 1996, 285 ss. 
traponen sistemas en los cuales el juez constitucional es especial por el parámetro, pues se pronuncia no sólo sobre las leyes, sino sobre cualquier acto, con tal de que la vulneración aducida lo sea de la Constitución, provenga ésta de quien provenga, arrebatando de este modo por entero la Constitución de las "garras" de los jueces ordinarios $^{49}$.

Otras soluciones alternativas indicativas de la difícil legitimidad de la justicia constitucional son la previsión de instrumentos que permiten al poder político superar las decisiones de los Tribunales constitucionales: aquí nos encontramos desde ordenamientos en los que se prevé que esto sólo pueda suceder mediante una revisión constitucional hasta ordenamientos en los que las mismas Constituciones contienen cláusulas de flexibilización que permiten a la ley ordinaria desatender las sentencias de los Tribunales constitucionales, como ocurre generalmente en los ordenamientos de inspiración británica. En estos últimos supuestos, las decisiones de los tribunales constitucionales tienden a aparecer como mensajes al Parlamento en forma jurídica ${ }^{50}$.

A la misma influencia pueden reconducirse las previsiones presentes en muchos ordenamientos que, distinguiendo el momento declarativo de inconstitucionalidad del momento constitutivo, aceptan que el Tribunal Constitucional pueda postergar los efectos de sus sentencias con el objeto de dar tiempo a una intervención del legislador. Piénsese, por ejemplo, en las sentencias de mera incompatibilidad o de inconstitucionalidad constatada pero no declarada, propias de las experiencias alemana y austríaca.

En conclusión, han sido los propios Tribunales constitucionales los que en su jurisprudencia han desarrollado instrumentos para acrecentar su "soportabilidad" para el sistema político. A esta exigencia pueden adscribirse algunas técnicas de decisión que permiten "medir» el juicio de racionalidad, como la ponderación, la preocupación de los Tribunales por

49 Muchos factores inciden en la opción por uno u otro modelo, no siendo el menos determinante la desconfianza hacia los jueces ordinarios, particularmente fuerte en las fases de transición a la democracia, como demuestra la reciente experiencia, a la que ya nos hemos referido, de los países de la Europa centro-oriental.

$50 \mathrm{~V}$. al respecto los distintos ensayos que recoge el libro P. Alston (coord.), Promoting Human Rights Through Bill of RigQxłord University Press, Oxford, 1999; más específicamente, F. RosA, "Limiti ai diritti e clausole orizzontali: Canada, Nuova Zelanda, Israele e Sudafrica a confronto", en Diritto pubblico comparato ed 
motivar suficientemente sus sentencias y, en general, por la transparencia de la motivación (permitiendo el voto particular), el self-restrajütucticial y la doctrina de las political quest,iademás de la creación de tipos de sentencia que limitan (en el tiempo o en el espacio) el impacto de sus sentencias de inconstitucionalidad ${ }^{51}$.

El desarrollo de estos instrumentos, si por un lado consiente una más fácil convivencia entre política y jurisdicción, entre gubernaculume iurisdictṕodríamos decir con palabras más elevadas, amenaza, por otro, con poner en duda la efectividad de la justicia constitucional, y en particular su capacidad para garantizar los derechos subjetivos reconocidos constitucionalmente.

51 Sobre esta tendencia se remite a T. GROPPI, «¿Hacia una justicia constitucional 'dúctil'? Tendencias recientes de las relaciones entre Corte constitucional y jueces comunes en la experiencia italiana", en Ferrer McGregor, E. (coord.) Derecho procesal 